\title{
Does Workplace Diversity Matter? A Survey Of Empirical Studies On Diversity And Firm Performance, 2000-09
}

Anne M. McMahon, Williamson College of Business Administration, USA

\begin{abstract}
This study seeks to assess the state-of-the-art on the workplace diversity - firm performance relationship. Based on a review of academic research on workplace diversity and firm performance published in nine leading journals in the field of management during the period 2000-2009, it addresses the following research questions: a. How are diversity and firm performance constructs defined? $b$. What are the findings of research linking workplace diversity and firm performance? $c$. What factors mediate and/or moderate the diversity-performance relationship? Based on the findings of extant research, we develop a model to explain and interpret the diversity - firm performance relationship, and understand its implications.
\end{abstract}

Keywords: Diversity, Performance, Workplace

\section{INTRODUCTION}

ssues relating to workplace diversity have become increasingly important in recent years. This is not surprising considering the far reaching changes in the competitive landscape immediately before of the advent of the new millennium that radically transformed the corporate workplace. Powerful political and technological forces led to revolutionary changes in the global business environment in the final decade of the last century. The dissolution of the erstwhile Soviet block symbolized by the fall of the Berlin Wall in 1989, the entry of China as a major player facilitated by normalization of its relations with the West, and the opening up of the emerging economies in Asia and Latin America spurred by policies of economic liberalization have not only opened up new markets for the expansion of US multinationals but also led to a reverse flow of goods, people and ideas into the US on an unprecedented scale. Both these trends were accentuated by technological innovation and the convergence of video, voice and data brought about by the Internet. The "race for markets" and the "race for the future" (Doz and Hamel, 1998) complemented each other in a symbiotic fashion to add cultural diversity to the melting pot of gender and ethnic diversity and radically transform the US workplace in the $21^{\text {st }}$ century. Not surprisingly therefore, workplace diversity has attracted widespread attention of academics and businesses alike.

Realizing the importance of leveraging diversity to achieve a competitive advantage, companies have incorporated diversity training in their employee orientation and development programs in the United States (Holladay, Knight, Paige and Quinones 2003). About two-thirds of the employers provide diversity training (CBLO 2006). Diversity training has in recent years expanded from an emphasis on equal opportunity themes typical of such training programs since the 1960's. Now-a-days, the training programs also emphasize acquisition of diversity competencies necessary for effective business strategy and assessing their effects on performance outcomes (Holladay et al. 2003). Diversity competence, both at organizational and individual levels, is now seen as critical to remain competitive in an increasingly global marketplace and in diverse employee labor markets (De Anca and Vazquez 2007). Academic researchers in the business fields for their part inter alia focused on modeling the nexus between workplace diversity and firm performance, presumably to provide a rationale and suggest ways to improve the practitioners' initiatives and thereby enhance the diversity competencies of their workforce. 
An interesting and instructive research issue would therefore be to assess the state-of-the-art on the workplace diversity - firm performance relationship. In what ways and under what circumstances does diversity contribute to firm performance? Is the relationship between the two necessarily linear and positive? What insights could practitioners gain from empirical research studies that investigated this relationship thus far? With this perspective, we formulated three research questions to explore by reviewing the academic research on workplace diversity and firm performance published during the last decade, i.e., 2000-2009.

1. How are the diversity and firm performance constructs defined and measured?

2. What are the findings of research linking workplace diversity and firm performance?

3. What factors, if any, mediate and/or moderate the diversity-performance relationship?

In order address these questions we carried out a survey of empirical studies on workplace diversity and firm performance during the period 2000 - 2009. A set of nine leading journals in the field of management were identified and all the articles dealing with workplace diversity and firm performance published during this period were reviewed in order to answer the research questions. The journals included in this survey were: Academy of Management Journal, Human Resource Management, Journal of Management, Journal of Management Studies, Management International Review, Management Science, Organization Science, Organizational Behavior \& Human Decision Processes and Strategic Management Journal. These journals were selected for the following reasons:

1. They are widely believed to be top journals as could be discerned from several lists of journal rankings in the fields of management, strategy and human resources (Harzing, 2009; McWilliams, Siegel, and Van Fleet, 2005);

2. They attract contributions from management scholars in general as well as scholars of strategy and HR;

3. Taken together, they employ a range of eclectic empirical methodologies in their studies - quantitative and qualitative, descriptive as well as prescriptive.

These journals represent visible, respected outlets for scholars and practitioners interested in a cross section of diversity- firm performance issues. A search by word in the Business Source Complete database of business periodicals, using multiple variations to refer to workplace diversity and firm performance resulted in a total of 50 hits. The subset of articles included in this survey was delimited after a careful perusal of the abstracts of all the results of the search by word. All empirical studies relating diversity to firm performance published during the period 2000 to 2009 were invariably included in the subset. Meta-analyses that summarized findings of earlier research on this relationship but published during the captioned period were also included in the survey. Studies with an essentially theoretical focus that do not use any empirical method were excluded from the list as being outside the scope of this survey. Studies that related diversity to group effectiveness, cohesion, and similar outcomes of group processes were excluded since the performance focus of our study is at the firm level. However, we made an exception to studies relating diversity and top management team (TMT) effectiveness in light of the consensus in extant research that TMT effectiveness is correlated with firm performance (Barrick, et.al., 2007; Lin and Shih, 2008). Applying these criteria to the master list of search results yielded a total of 24 articles as detailed in Table 1.

Table 1: Workplace Diversity and Firm Performance - Distribution of Research Studies by Journal (2000-2009)

\begin{tabular}{clc}
\hline S. No. & Name of the Journal & Number of Articles Published \\
\hline 1. & Academy of Management Journal & 3 \\
2. & Human Resource Management & 2 \\
3. & Journal of Management & 2 \\
4. & Journal of Management Studies & 2 \\
5. & Management International Review & 2 \\
6. & Management Science & 2 \\
7. & Organization Science & 1 \\
8. & Organizational Behavior \& Human Decision Processes & 1 \\
9. & Strategic Management Journal & 24 \\
\hline
\end{tabular}




\section{Race/Gender Diversity and Firm Performance}

In a study of the U.S. banking industry, Richard (2000) explored the relationship between racial diversity of the workforce and the firm's beliefs on diversity on the one hand, and financial performance on the other in a sample of 63 banks. The banks were drawn from three states: California for its high racial diversity, Kentucky due to its low racial diversity, and North Carolina for the banks' financial wealth and asset size. Blau's index of heterogeneity was used to assess workforce diversity of the banks. Financial information was obtained from the Shesunoff Bank Search database. The independent variable for this study was the racial background of bank employees (white, black, Hispanic, Asian, and Native American). The dependent variables were: productivity, return on equity, and market performance. Firm size, state differences, gender, mix of loan portfolio, geographic scope, and banks' attitude towards racial diversity were controlled. Although the hypothesis that racial diversity would be positively linked to firm performance was not supported, the firms' business strategy was found to moderate the relationship between the two. Thus, when a firm pursued a strategy of growth there was a positive relationship between racial diversity and firm performance while the relationship was negative when the strategy was one of downsizing.

In a related study, Richard, Barnett, Dwyer and Chadwick (2004) added gender and the degree of entrepreneurial orientation of the firm to the racial diversity of manager and supervisor groups as variables, and studied the responses from 535 bank presidents and human resource executives. Covin and Slevin (1989)'s nineitem entrepreneurial scale was used to measure three dimensions of entrepreneurial orientation: innovativeness, risk taking, and proactiveness. Firm performance was measured by labor productivity (net income per employee) and the average return on equity for the preceding two years. The proportions of whites and men (due to a large majority in sample), firm size, and annualized percentage of asset growth were controlled. The hypothesized U-shaped curvilinear relationship between cultural diversity in management and firm performance was not supported. However, it was found that the curvilinear relationship would be positive and moderately strong in firms with an innovative orientation, and moderately negative in firms with a risk taking orientation when the diversity is very high or vey low. Proactive entrepreneurial orientation had no impact on the relationship.

Broadening their study beyond the U.S. banking industry to include a range of other industries, Richard, Murthi, and Ismail (2007) investigated the impact of racial diversity on intermediate and long-term firm performance and the moderating role of the environmental context. Using data from Fortune magazine's diversity survey for the years 1997 through 2002, they estimated the models employing ordinary least squares regression (OLS). Firm Performance was measured by labor productivity and Tobin's q (ratio of market value to asset replacement value). Firm size, R\&D, net income, and the cost of goods sold were controlled.

Racial diversity displayed a curvilinear positive relationship to intermediate firm performance at low or high levels of diversity. Racial diversity also exhibited a positive correlation to long-term firm performance. The type of industry was found to moderate the strength of the relationship between the two. Thus, the predicted Ushaped relationship between racial diversity and firm performance would be more noticeable in service industries than in manufacturing industries. The linear relationship between racial diversity and long-term performance would be stronger in resource rich environments. Environmental instability would negatively moderate this relationship i.e., the U-shaped relationship between firm performance and racial diversity would be stronger in stable environments than in unstable environments.

Despite these important findings, it is recognized by scholars that diversity measured by single attributes alone might not provide conclusive evidence of the impact of workplace diversity on firm performance. Lau and Murnighan (2005) therefore investigated the effects of demographic faultlines on the interactions within groups and subgroups. It was observed that intra-group and cross-subgroup communications affected demographic faultlines. If members of a group fall into more than one non-overlapping subgroups based on demographic characteristics e.g., young Chinese women and old African men, a strong "faultline" is said to be present in the group. Faultlines could explain better why the perceptions of team learning, psychological safety, satisfaction, and expected performance vary than single attribute heterogeneity indexes. The faultline model used in this study suggested that when a group is split into subgroups, people associate their identities more with their subgroups than with their entire groups. 
It was found that members of strong faultline groups evaluate members of their subgroups more favorably than do members of weak faultline groups. The identification of subgroups could accentuate members' awareness of a subgroup's boundary and their feelings of belonging. When outcomes depend more on their subgroups' actions, people tend to focus on subgroups rather than entire groups' actions. Group members are more likely to communicate and share information within rather than across their subgroups when demographic faultlines are strong. Groups with strong faultlines experience more intra-group conflict and poorer group outcomes (e.g., rating of their task and relationship conflict, group learning, psychological safety, satisfaction and expected group performance) than do groups with weak faultlines. The effects of cross-subgroup communications are moderated by group faultlines.

Effective management of diversity is based on recognition of commonalities and awareness of differences. Role modeling behaviors of those who readily accept the differences could help alter the organizational culture, and thereby improve performance outcomes. Globalization and diversity have increased the need for investigation into workplace attitudes towards diverse others. In a study of topical relevance, Strauss and Connerley (2003) explored the relationships between race, gender, agreeableness, openness to experience, contact and cognitions, feelings \& behaviors. The Universal-Diverse Orientation (UDO) construct was employed as a measure of attitudes towards diversity. This metric has three components: realistic appreciation (cognition), comfort with difference (feeling) and diversity of contact (behavior).

Based on a survey of 252 undergraduate business students from two different institutions in the US, the study found partial support for the hypothesis that women and non-Whites have more positive UDO attitudes. Gender plays a role only as a first step. Persons who rate high on openness to experience would have more positive UDO attitudes. Surprisingly, the findings did not support the view that people living in more heterogeneous environments would have more positive UDO attitudes. Contact, gender and race would interact with openness and agreeableness to predict UDO attitudes. Women had more favorable attitudes at high levels of openness than men. The findings suggest that the cognitive and affective components of UDO attitudes were impacted by agreeableness alone, and the behavioral component was significantly related to race, agreeableness, openness and contact when all variables were included in the model. Agreeableness emerged as the most important predictor of attitudes.

Diversity in business helps in pooling the best talent, reduces the gap between increasingly diverse customer bases, unleashes creativity, promotes innovation and thereby enhances the competitiveness of the organization. Extending the concept of diversity from attributes like race, gender, age etc to the entire spectrum of human differences Jayne and Dipboye (2004) proposed that crucial to changing the workforce are efforts to recruit, retain and develop employees from under-represented groups as well as creating internal structures to sustain an effective diversity program. Using behavioral interviews, biographical data inventories, assessment centers, work samples etc to assess KSAOs (knowledge, skills, abilities, experiences and other characteristics), this study suggests that effective diversity programs should strike a balance between identifying right KSAOs and enhancing them through training. Employing a "relational demography" method, the study found that working with dissimilar others often results in negative outcomes. Increased group level diversity does not necessarily lead to higher performance and a diverse group is not always a better-performing group. Based on two surveys and a review of extant research, the study found that benefits of diversity are contingent up on situational factors such as organizational culture, strategies and the environmental context. Successful diversity programs should be based on specific goals and not quotas for minority groups.

The study makes the important point that the success of diversity programs depends on how they are framed. Rather than as threats to overcome, they should be framed as challenges and opportunities. Comparing the relative efficacies alternative approaches to framing, the integration and learning perspective (rethinking primary processes) is recommended as the most effective in sustained motivation of management and employees for long term success. Having a diverse top management team is the most powerful way to signal the support for diversity. Drawing up on social identity theory, the research suggested encouraging employees to know each other as individuals so as to overcome stereotyping, prejudice and intergroup conflicts resulting from an in-group association based on likeness to oneself. 
Organizations can manage diversity effectively by building senior management commitment and accountability with a thorough needs assessment of the people. Employee surveys, focus groups and exit interviews could be useful in uncovering issues faced by the organization. Developing a well developed strategy to realize realistic business goals also ensures diversity success. As noted earlier, the Richard (2000) study found a positive relation between racial diversity and firm performance in organizations pursuing a growth strategy. Finally, establishing metrics and evaluating the effectiveness contributes to success. Increasing diversity alone does not guarantee immediate tangible improvements. Nevertheless creating a diverse workforce could yield huge benefits.

The "business case" for diversity - the view that more diversity would increase performance effectiveness is gaining momentum because of talent shortage and an increasingly diverse customer base. A report of the Diversity Research Network (Kochan, et al., 2003) based on a large field based 5-year research project summarizes the findings from the case studies of four large firms in the information processing, financial services, and retailing industries on the relationship between race/gender diversity and business performance. The studies variously measured performance, satisfaction and turnover and related them to cultural, demographic, technical and cognitive diversities. They had also measured group processes of communication, conflict, cohesion, information and creativity within the organizational context of culture, business strategy and HR policies. Qualitative data on business unit cultures, HR and managerial practices, survey data based on quality of group processes and census data on demographic composition of teams were used to interpret the results. The studies established few direct effects of diversity on performance (positive or negative). The report looks beyond the existing business case by adopting an analytical approach of linking HR practices to business performance. It supports experimentation and evaluation and not simply sticking to the old frame of the business case. To inculcate a culture of mutual learning and cooperation, organizations should implement appropriate management and HR policies in addition to training programs for diversity management.

Recognizing the complex relationship between team diversity and team outcomes, the mixed nature of the evidence and the moderating variables potentially affecting this relationship in extant research, Horwitz and Horwitz (2007) carried out a meta-analytic review of studies published between 1985 and 2006 to provide quantitative estimates of the relationship. A total of 78 correlations from 35 articles were included for the purpose. Correlation coefficient on randomized experiments and post hoc analysis were used as tools to better understand the hypothesized relationships. Based on a dichotomization of team diversity variable into task-related versus biodemographic diversity, they tested the hypothesis of synergistic performance resulting from diverse employee teams. Although bio-demographic diversity was not significantly related to team performance, the positive impact of taskrelated diversity on team performance was supported. Similarly, there is no discernible effect of team diversity on social integration.

Employing the idiom of melting pot versus tossed salad, Bachmann (2006) explored what it takes to design an effective multicultural team in the workplace. The study distinguishes between two types of coupling in workgroups: structural and cultural. Structural coupling refers to the task-related domain, and cultural coupling refers to non-task related social domain. The most effective multicultural groups tend to have a tight coupling in task related structural domain and loose coupling in non-task cultural domain. While the former results in consensus, cohesion, effectiveness and stability, the latter leads to diversity, accuracy, creativity and flexibility. Structural coupling could be achieved by clarifying the group's objectives, dividing group tasks into interdependent subtasks, assigning task roles, allocating responsibilities and authority and determining the norms of task related interactions. The cultural coupling is accomplished by creating an atmosphere of mutual respect and acceptance, and signaling approachability for smoothing differences. In short, an effective workgroup needs to be both a tossed salad and a melting pot for the best possible outcomes.

Based on the premise that effective work groups tend to exchange and share knowledge with external constituencies such as customers, organizational experts and others outside the group Cummings (2004), based on a field study of 182 workgroups in a Fortune 500 telecom company, concluded that the value of external knowledge sharing increases when such groups are structurally more diverse. Structural diversity is operationlized in terms of member differences in geographic locations, functional assignments, reporting managers, and business units. External knowledge sharing was measured using group member surveys and performance was estimated using senior executive ratings. The study concluded that the interaction of external knowledge sharing and geographic 
locations was significantly associated with the performance. The greater the external knowledge sharing, the better the performance, when there were more geographic locations. It was also found that external knowledge sharing was related to better performance when there were more functional assignments. The interaction of external knowledge sharing and reporting managers was also significantly associated with performance. However, there was only partial support for the effect of structural diversity based on the number of business units.

Based on a study of 437 teams in 46 units of a large US company, Joshi, Hui and Jackson (2006) concluded that in-group/out-group dynamics of diverse workgroups might contribute to sales performance differences between members of higher-status majorities and lower-status minorities. The study employed measures such as individual demographic attributes, work team composition, management composition of work units, and sales performance. The control variables were age and tenure of service to account for differences in human capital. It is possible that all employees experience both in-group favoring and out-group discrimination. As the in-group size increases, the members of the in-group enjoy benefits of in-group dynamics. On the other hand, as the in-group size decreases the group suffers from costs arising from out-group discrimination. Status is also an important factor in the performance implications of workplace diversity. It is frequently observed that men and whites typically enjoy higher status than women and people of color. Because status is usually associated with skill and expertise, men and whites may be valued and rewarded even when they are in a minority or token position.

\section{Tmt Diversity And Firm Performance}

Earlier research studies had typically explored the direct link between TMT demographic characteristics and firm performance presumably due to ready availability of demographic data. The support for the relationship was at best modest or the findings were mixed. In contrast, Certo, Lester, Dalton, and Dalton (2006) employed confirmatory factor analysis to investigate the moderating influences in this relationship. TMT heterogeneity was assessed using four measures: size, organizational tenure, functional, executive tenure and educational. Firm performance was defined in terms of Return on Assets, 3 year average ROA, ROA growth, 3 year average Return on Equity, and sales growth. The study concluded that TMT size and financial performance are partially correlated with a positive and significant relationship between TMT size and sales growth but no evidence of the effect of TMT size on ROA or ROE. There is also a partial positive relationship between TMT heterogeneity and firms' financial Performance with functional heterogeneity and executive tenure heterogeneity being positively related with ROA. The study also found that several TMT variables were significantly related to strategic variables such as diversification, $R \& D$ expenditures and internationalization.

Applying the theoretical lenses derived from signaling theory and the behavioral theory of the firm, Miller and del Carmen (2009) investigated how firm reputation and innovation mediated the board diversity-firm performance relationship. The independent variables in the study were board diversity, innovation, and firm reputation. Board diversity was assessed on the basis of race and gender. Innovation was measured by R\&D expenditures. Firm reputation was based on the 2004 Fortune Corporate Reputation Survey. Firm performance was measured using the accounting based measures of ROI and ROS. Firm age, liquidity, size, product diversification, international diversification, and industry were controlled. The study based on a sample of Fortune 500 firms, found a positive relationship between board racial diversity and both firm reputation and innovation. Reputation and innovation both partially mediated the relationship between board racial diversity and firm performance. Further there was a positive relationship between board gender diversity and innovation.

Employing the MARKSTRAT simulation, which is widely used to study decision making, Kilduff, Angelmar and Mehra (2000) investigated the role of cognitions in the TMT diversity-firm performance relationship. The diversity variables included in the study were nationality, functional heterogeneity (computed using Blau's index), age heterogeneity and cognitive diversity. Firm performance was measured by net contribution margin and market share. The study conducted on a sample of 159 managers split into 35 teams revealed that the higher the interpretive ambiguity of top management teams, greater the firm performance.

Earlier research studies had also paid scant attention to the nature of TMT team processes that interact with TMT compositional diversity in influencing firm performance outcomes. Boone and Walter (2009) sought to address this gap by investigating how team mechanisms such as collaborative behavior, accurate information 
exchange, and decision-making decentralization moderate the impact of TMT diversity on financial performance of 33 information technology firms - 14 Belgian and 19 Dutch. All the firms operated in software services and products industries. TMT diversity was defined in terms of functional-background (FB) and locus-of-control (LOC). While the former could potentially enhance decision quality and organizational performance, the latter could lead to relational conflict and thereby adversely impact firm performance. The study found that functional background diversity is positively related to firm performance. A TMT's collaborative behavior and information exchange are prerequisites to reap the performance benefits of FB diversity but avoids the negative effects of LOC diversity. Further, decentralized decision making while enhancing the effectiveness of functionally diverse teams, also reinforces the negative consequences of LOC diversity on firm performance.

Researchers generally tend to overlook the impact of nationality diversity within subsidiary TMTs on subsidiary performance. Drawing up on theoretical insights from knowledge and legitimacy perspectives, Gong (2006) enquired into this important dimension of diversity using a large sample of 370 subsidiary TMTs with a total of 2290 top managers in 28 Japanese multinationals. Firm performance was measured using subsidiary labor productivity. Industry, TMT size, number of years a subsidiary was in operation, capital investment and gross national income per capita of the host country were controlled. The study concluded that there was a significant positive correlation between nationality heterogeneity and subsidiary performance. Furthermore, as the number of years the subsidiary was in operation increased, the effect of subsidiary TMT nationality heterogeneity became more positive. Thus, national diversity becomes more important when it is more pertinent to a team's work.

\section{Diversity-Firm Performance Relationship: The Role Of Context}

Focusing on the moderating effects of internal and external contexts, Cannella, Park and Lee (2008) investigated the effect of co-location of TMT members and environmental uncertainty on the TMT diversity-firm performance relationship. Based on a study of 207 U.S. firms in 11 industries, the study concluded that the effects of TMT functional diversity on firm performance would be more positive as the proportion of TMT members with offices in the same location increases. The effects of intrapersonal functional diversity would also be more positive as environmental uncertainty increases.

Summarizing the results from 39 studies, Joshi and Roh (2009) in a meta-analytic study explored the role of contextual factors at multiple levels - industry, occupation and team, in influencing performance outcomes of relations-oriented and task-oriented diversity. It was found that although the direct effects of contextual factors were small yet they were significant. After accounting for industry, occupation, and team-level contextual moderators, the effects doubled, and in some cases even tripled, in size. Moreover, occupation and industry-level moderators explained significant variance in effect sizes across studies.

The hypothesized negative effect of gender and race/ethnicity diversity would be weaker in more gender and ethnically balanced settings was confirmed. That the positive performance outcome of task-oriented diversity would be stronger in more balanced occupational settings was disproved implying higher performance outcomes in majority male and white settings. Results also showed that relations-oriented diversity had a positive effect on performance in service industries but the support was weak for the moderating effects of the industry setting on the performance outcome of task-oriented diversity. That the negative effects of relations-oriented diversity would be strengthened in long-term teams was also strongly supported.

\section{CONCLUSION}

What emerges from the foregoing annotated review of recent research linking workplace diversity and firm performance is a fascinating mosaic of insights and perspectives that enrich our understanding of both these concepts as well as their interrelationship. Academic research on this topic has indeed made great strides and attempts to dispel populist notions of the concept of diversity and how it could influence business performance. Diversity is no longer conceptualized simply in demographic terms such as race, gender, education, and so on. Even when it is expressed using these parameters, it is no longer uni-dimensional. Heterogeneity, even when such demographic criteria are applied, needs to recognize the relevance of overlaps among these criteria while considering workplace diversity i.e., "faultlines" (Lau and Murnighan, 2005), in order to derive meaningful 
inferences about diversity and how it would affect business performance. While bio-demographic diversity might be easy to recognize since it is apparent, task-related diversity and cognitive diversity are more important criteria to take cognizance of while attempting to understand workplace diversity and its true implications for firm performance. Thus, task related dimensions e.g., functional background, organizational tenure and experience, social psychological characteristics e.g., agreeableness, openness to experience, contact and cognitions, feelings and behaviors, and team interaction abilities e.g., attitudes towards others, acceptance of differences, etc are equally if not more relevant to assess workplace diversity and explain its influence on performance outcomes.

Contemporary research has also expanded the concept of firm performance in exploring the effect of workplace diversity. While financial performance continues to be used to estimate performance outcomes in the short term e.g., various measures of firm profitability such as Return on Assets, Return on Sales, and Return on Equity, and in the long term e.g., Tobin's q, market share, etc, there is a trend in academic research to look beyond financials to assess the performance implications of diversity. Slowly but surely, scholars are incorporating metrics such as quality of results, social integration, decision making, creativity and problem solving, and other outcomes e.g., Knowledge, skills, abilities, experiences and other characteristics (KSAOs), task and relationship conflict to measure performance. Thus, the concepts of both workplace diversity as well as firm performance are now infused with new meaning and significance, as these should be, while exploring their interrelationship. A summary of measures of diversity and firm performance as used in empirical studies on this topic during the captioned period is presented in Table 2 .

The impact of workforce diversity, in its richer connotation, on firm performance is no longer considered as linear. For the present it is hypothesized to be curvilinear, U-shaped and having larger effects at high as well as low degrees of diversity. Such effects appear to be stronger in stable rather than in unstable environments. The effects of diversity also seem to be more pronounced in service industries than in manufacturing industries. This phenomenon might be due to the greater degree of interpersonal interactions in service industries such as hospitality, commercial airlines wherein personalized customer service is likely to influence firm performance. While contextual factors are important, the relationship between workplace diversity and firm performance is neither direct nor definitive. This is clear from the mixed results of empirical studies attempting to establish this nexus. Diversity by itself alone can not account for differential performance among firms. Certain firm-specific factors such as resources, capabilities, and core competencies are more likely to account for such performance outcomes. It is interesting to note that current research on the performance implications of workplace diversity recognizes this reality and is thus in tune with the findings of research in strategic management. Diversity that enhances firm resources, capabilities, and core competencies is more likely to lead to superior firm performance. Thus, the mediating factors identified by researchers in the area of diversity-performance include KSAOs - Knowledge, skills, abilities, experiences and other characteristics, entrepreneurial orientation, firm reputation, innovation, knowledge sharing and so on. Thus, we see an emerging convergence in the views of scholars of diversity and strategy on how diversity is an important factor to understand and leverage for superior firm performance. Diversity research has also recognized the importance of organizational culture in enabling firm performance. Moreover, this research stream realizes that the diversity variable becomes more important when the business strategy is growth-oriented rather than one where there is downsizing that could work against workplace diversity due to traditional biases. The workplace diversity -firm performance relationship as it emerges from the survey of recent empirical research is modeled as captured in Figure 1. 
Table 2

Workplace Diversity and Firm Performance: Measures of Variables

\begin{tabular}{|c|c|c|}
\hline Research Study & Measure(s) of Workplace Diversity & Measure(s) of Firm Performance \\
\hline Bachmann (2006) & Structural and Cultural Differences & Group Effectiveness and Efficiency \\
\hline Boone \& Walter (2009) & $\begin{array}{l}\text { Functional-background } \\
\text { Locus-of-control }\end{array}$ & Return on Sales \\
\hline Cannella, Park \& Lee (2008) & TMT functional background (functional experience, age, tenure); co-location & Return on Assets \\
\hline $\begin{array}{l}\text { Certo, Lester, Dalton, \& Dalton } \\
(2006)\end{array}$ & $\begin{array}{l}\text { TMT Size, organizational tenure, functional, executive, tenure and } \\
\text { educational heterogeneity }\end{array}$ & $\begin{array}{l}\text { Return on Assets, } 3 \text { year average ROA, ROA growth, } 3 \text { year } \\
\text { average Return on Equity, and sales growth }\end{array}$ \\
\hline Cummings (2004) & Geographic locations, functional assignments, reporting managers & $\begin{array}{l}\text { Problem Definition, Method Selection, Innovation, Result } \\
\text { Quality, Clarity of Presentation }\end{array}$ \\
\hline Gong (2006) & Nationality & Labor productivity \\
\hline Horwitz \& Horwitz (2007) & $\begin{array}{l}\text { Task-related Vs Bio-demographic diversity, } \\
\text { Cognitive diversity }\end{array}$ & $\begin{array}{l}\text { Quantity and Quality of Performance, Social Integration, Team } \\
\text { Cohesion, Decision Making, Creativity and Problem Solving }\end{array}$ \\
\hline Jayne and Dipboye (2004) & $\begin{array}{l}\text { Race, multicultural organizations, psychological framing, management } \\
\text { diversity initiatives }\end{array}$ & $\begin{array}{l}\text { KSAOs: Knowledge, skills, abilities, experiences \& other } \\
\text { characteristics Individual reactions to work situations based on } \\
\text { 'relational demography' }\end{array}$ \\
\hline Joshi \& Roh (2009) & $\begin{array}{l}\text { Task-oriented: Function, education, \& tenure } \\
\text { Relations-oriented: Gender, race/ethnicity, \& age }\end{array}$ & Various \\
\hline Joshi, Hui \& Jackson (2006) & $\begin{array}{l}\text { Individual demographic attributes: Tenure, age, gender, \& ethnicity } \\
\text { Work team composition: Proportion of women and color in each team } \\
\text { Management composition of work units: Location \& size/number of clients }\end{array}$ & Sales revenue, Pay \\
\hline Kilduff, Angelmar \& Mehra (2000) & Nationality, functional heterogeneity, age $\&$ cognitive diversity & $\begin{array}{l}\text { Net contribution margin } \\
\text { Market share }\end{array}$ \\
\hline Kochan, et al., (2003) & Race, gender, group processes, and regional diversity & Performance satisfaction, Turnover, Quality of group processes \\
\hline Lau \& Murnighan (2005) & $\begin{array}{l}\text { Gender } \\
\text { Ethnicity }\end{array}$ & $\begin{array}{l}\text { Task and relationship conflict, group learning, psychological } \\
\text { safety, satisfaction and expected group performance }\end{array}$ \\
\hline Miller \& del Carmen (2009) & Boardroom diversity: Race and Gender & $\begin{array}{l}\text { Financial performance: ROI, ROS } \\
\text { Firm innovation: R\&D expenditure } \\
\text { Firm reputation }\end{array}$ \\
\hline Richard (2000) & Ethnicity & Productivity, ROE, and Market Performance \\
\hline $\begin{array}{l}\text { Richard, Barnett, Dwyer \& Chadwick } \\
\text { (2004) }\end{array}$ & $\begin{array}{l}\text { Ethnicity } \\
\text { Gender } \\
\text { Degree of entrepreneurial orientation }\end{array}$ & $\begin{array}{l}\text { Labor Productivity (Net income/employee) } \\
\text { Average ROE for the preceding two years }\end{array}$ \\
\hline Richard, Murthi \& Ismail (2007) & Ethnicity & $\begin{array}{l}\text { Labor productivity (Revenue/employee), } \\
\text { Tobin's q (Market value /Asset replacement value) }\end{array}$ \\
\hline Strauss \& Connerley (2003) & $\begin{array}{l}\text { Race, gender, agreeableness, } \\
\text { openness to experience, contact and cognitions, feelings \& behaviors }\end{array}$ & $\begin{array}{l}\text { Universal Diverse Orientation: Measure of attitudes- realistic } \\
\text { appreciation, comfort with distance and diversity of contact }\end{array}$ \\
\hline
\end{tabular}


Figure 1

Workplace Diversity -Firm Performance Relationship: A Model

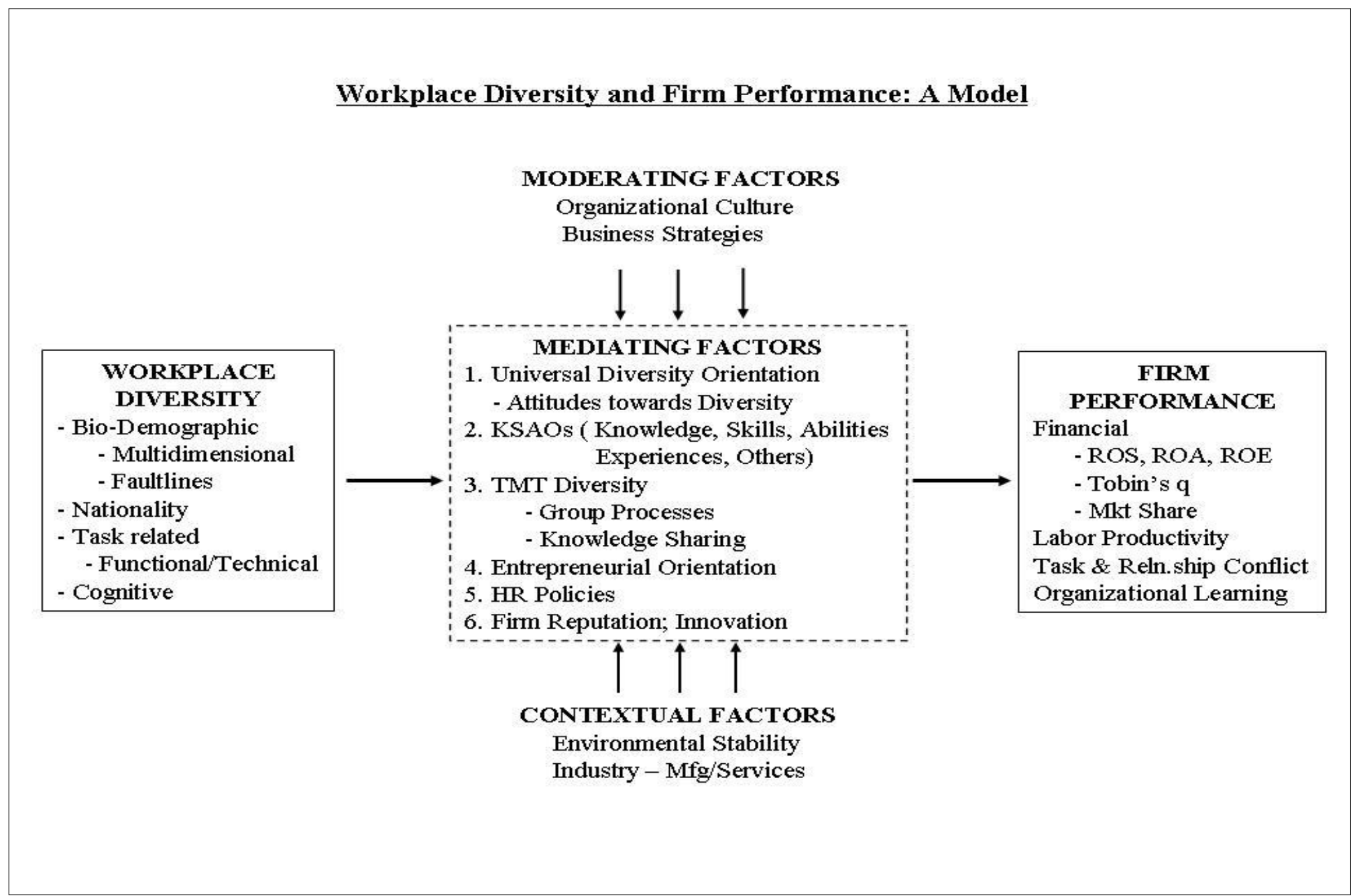


The instrumental implications of workplace diversity are doubtless important to businesses, and therefore diversity needs to be managed. In doing so, one could be "reactive" to deal with the phenomenon of diversity. A better approach might be to be "proactive" in leveraging diversity to achieve superior business performance. However, it is important to recognize that diversity is a fact of life in today's workplace. It is a reality as much as sustainability and achieving energy efficiency are in the $21^{\text {st }}$ century. The proper approach should therefore be "interactive" and designed to work with all stakeholders to achieve their individual and organizational goals as well as societal imperatives (Post, 1978). There is a need to adopt a "normative" rather than an "instrumental" approach to workplace diversity because that is the right thing to do in terms of social justice, community engagement and rationale based on globalization of the business environment.

\section{AUTHOR INFORMATION}

Anne McMahon is Professor of Management in the Williamson College of Business Administration at Youngstown State University where she teaches Organizational Behavior and Workplace Diversity. She has served several terms on the national Workplace Diversity Panel of the Society for Human Resources Management. She organizes community leaders in the Partners for Workplace Diversity, an alliance of over 30 organizations to develop diversity initiatives for the Partnership and for the community at large (www.ysu.edu/workplacediversity).

\section{REFERENCES}

1. Bachmann Anne S., Melting Pot or Tossed Salad? Implications for Designing Effective Multicultural Workgroups, Management International Review, Vol. 46, No. 6, pp. 721-747, 2006.

2. Barrick, Murray R., Bret H. Bradley, Amy L. Kristof-Brown and Amy E. Colbert, The Moderating Role of Top Management Team Interdependence: Implications for Real Teams and Working Groups, Academy of Management Journal, Vol. 50, No. 3, pp. 544-557, 2007.

3. Boone, Christophe and Walter Hendriks, Top Management Team Diversity and Firm Performance: Moderators of Functional-Background and Locus-of-Control Diversity, Management Science, Vol. 55, No. 2, pp. 165-180, 2009.

4. Cannella Jr., Albert A., Jong-Hun Park and Ho-Uk Lee, Top Management Team Functional Background Diversity and Firm Performance: Examining the Roles of Team Member Colocation and Environmental Uncertainty, Academy of Management Journal, Vol. 51, No. 4, pp. 768-784, 2008.

5. CBLO. New Data on Diversity Training, Compensation \& Benefits for Law Offices, Vol. 6, No. 2, pp. 9, 2006.

6. Certo, S. T., Richard H. Lester, Catherine M. Dalton and Dan R. Dalton, Top Management Teams, Strategy and Financial Performance: A Meta-Analytic Examination, Journal of Management Studies, Vol. 43, No. 4, pp. 813-839, 2006.

7. Covin, Jeffrey G. and Dennis P. Slevin, Strategic Management of Small Firms in Hostile and Benign Environments, Strategic Management Journal, Vol. 10, No. 1, pp. 75-87, 1989.

8. Cummings, Jonathon N., Work Groups, Structural Diversity, and Knowledge Sharing in a Global Organization, Management Science, Vol. 50, No. 3, pp. 352-364, 2004.

9. De Anca, Celia and Antonio V. Vega, (Translated by Andy Goodall) Managing Diversity in the Global Organization, Palgrave Macmillan, New York, New York, 2007.

10. Doz, Yves L. and Gary Hamel, Alliance Advantage: The Act of Creating Value Through Partnering, Harvard Business School Press Books, Boston, Massachusetts, 1998.

11. Gong, Yaping, The Impact of Subsidiary Top Management Team National Diversity on Subsidiary Performance: Knowledge and Legitimacy Perspectives, Management International Review, Vol. 46, No. 6, pp. 771-789, 2006.

12. Harzing, Anne-Wil. Journal Quality List, 34th Edition, University of Melbourne, Parkville, Australia, 2009.

13. Holladay, Courtney L., Jennifer L. Knight, Danielle L. Paige and Miguel A. Quiñones, The Influence of Framing on Attitudes Toward Diversity Training, Human Resource Development Quarterly, Vol. 14, No. 3, pp. 245-263, 2003.

14. Horwitz, Sujin K. and Irwin B. Horwitz, The Effects of Team Diversity on Team Outcomes: A MetaAnalytic Review of Team Demography, Journal of Management, Vol. 33, No. 6, pp. 987-1015, 2007. 
15. Jayne, Michele E. A. and Robert L. Dipboye, Leveraging Diversity to Improve Business Performance: Research Findings and Recommendations for Organizations, Human Resource Management, Vol. 43, No. 4, pp. 409-424, 2004.

16. Joshi, Aparna, Hui Liao and Susan E. Jackson, Cross-Level Effects of Workplace Diversity on Sales Performance and Pay, Academy of Management Journal, Vol. 49, No. 3, pp. 459-481, 2006.

17. Joshi, Aparna and Hyuntak Roh, The Role of Context in Work Team Diversity Research: A Meta-Analytic Review, Academy of Management Journal, Vol. 52, No. 3, pp. 599-627, 2009.

18. Kilduff, Martin, Reinhard Angelmar and Ajay Mehra, Top Management-Team Diversity and Firm Performance: Examining the Role of Cognitions Organization Science, Vol. 11, No. 1, pp. 21-34, 2000.

19. Kochan, Thomas, Katerina Bezrukova, Robin Ely, Susan Jackson, Aparna Joshi, Karen Jehn, Jonathan Leonard; David Levine and David Thomas, The Effects of Diversity on Business Performance: Report of the Diversity Research Network, Human Resource Management, Vol. 42, No. 1, pp. 3-21, 2003.

20. Lau, Dora C. and J. K. Murnighan, Interactions Within Groups and Subgroups: The Effects of Demographic Faultlines, Academy of Management Journal, Vol. 48, No. 4, pp. 645-659, 2005.

21. Lin, Hao-Chieh and Chih-Ting Shih, How Executive SHRM System Links to Firm Performance: The Perspectives of Upper Echelon and Competitive Dynamics, Journal of Management, Vol. 34, No. 5, pp. 853-881, 2008.

22. McWilliams, Abigail, Donald Siegel and David D. Van Fleet, Scholarly Journals as Producers of Knowledge: Theory and Empirical Evidence Based on Data Envelopment Analysis, Organizational Research Methods, Vol. 8, No. 2, pp. 185-201, 2005.

23. Miller, Toyah and María del Carmen Triana, Demographic Diversity in the Boardroom: Mediators of the Board Diversity-Firm Performance Relationship, Journal of Management Studies, Vol. 46, No. 5, pp. 755786, 2009.

24. Post, James E., Corporate Behavior and Social Change, Reston Publishing, Reston, VA, 1978.

25. Richard, Orlando C., Racial Diversity, Business Strategy, and Firm Performance: A Resource-Based View, Academy of Management Journal, Vol. 43, No. 2, pp. 164-177, 2000.

26. Richard, Orlando C., Tim Barnett, Sean Dwyer and Ken Chadwick, Cultural Diversity in Management, Firm Performance, and the Moderating Role of Entrepreneurial Orientation Dimensions, Academy of Management Journal, Vol. 47, No. 2, pp. 255-266, 2004.

27. Richard, Orlando C., B. P. S. Murthi and Kiran Ismail, The Impact of Racial Diversity on Intermediate and Long-Term Performance: The Moderating Role of Environmental Context, Strategic Management Journal, Vol. 28, No. 12, pp. 1213-1233, 2007.

28. Strauss, Judy P. and Mary L. Connerley, Demographics, Personality, Contact and Universal-Diverse Orientation: An Exploratory Examination, Human Resource Management, Vol. 42, No. 2, pp. 159-174, 2003 